www.jmscr.igmpublication.org

Impact Factor 5.244

Index Copernicus Value: 83.27

ISSN (e)-2347-176x ISSN (p) 2455-0450

crossref DOI: https://dx.doi.org/10.18535/jmscr/v4i12.126

\title{
Patient Compliance and Awareness with Thyroid Replacement Therapy
}

\author{
Authors \\ Dr Amer Ahmed Balla ${ }^{1}$, Hanan Ahmed Alanazi ${ }^{2}$, Maha Khalaf Alenazy ${ }^{3}$ \\ Sara Mohammed Otaywi ${ }^{4}$ \\ ${ }^{1}$ Assistant Professor of Internal Medicine \\ ${ }^{2,3,4}$ Intern, Faculty of Medicine, Northern Border University Arar, KSA
}

\begin{abstract}
Thyroid diseases notably hypoactive gland is challenging in northern borders region. Despite lack of clear statistical data, the disorder is one of the commonly seen health problems in the outpatient department.

Hypothyroidism is mostly diagnosed with ease as the clinical features are clear and the diagnostic tools are available and accurate.

This descriptive study is proposed to highlight patient awareness and compliance with thyroid hormone replacement therapy in northern borders region.
\end{abstract}

\section{Introduction}

Hypothyroidism is the most common endocrine disease, it is more prevalent among reproductive and middle age female

Once developed, hypothyroidism requires replacement therapy for life, except for the rare cases of acute thyroiditis which is self-limiting and iodine deficiency which can be treated in endemic areas with iodinated salt.

Thyroid hormone replacement therapy should be accompanied by patient education about the disease, the treatment dosage and timing and drugs interaction

Thyroxin is the commonly used drug to replace thyroid function, iron and calcium interfere with its absorption, in addition to acid lowering drugs like PPI and $\mathrm{H} 2$ blockers

\section{Methodology}

This is a retrospective descriptive study for the awareness of hypothyroidism and thyroid hormone replacement therapy among patients with hypothyroidism in Arar central hospital during the period of January 2015 - May 2016

Inclusion Criteria: all patients with primary and secondary hypothyroidism on thyroid hormone replacement therapy

Exclusion Criteria: any patient with thyroid cancer on large suppressive dose of thyroxin

For this study all patients diagnosed with hypothyroidism in Arar during the period 2015 to May 2016 are included in the study.

\section{Steps}

Data were collected from patients diagnosed to have hypothyroidism and on thyroid hormone replacement therapy

$>$ Computer Information Entrance

$>$ Result

$>$ Discussion and Conclusion

Data were collected through direct electronic formulated questionnaire. 
Data collection

\begin{tabular}{|l|c|c|}
\hline age & number & Percentage \\
\hline $20-30$ & 152 & $40.1 \%$ \\
\hline $31-40$ & 158 & $40.7 \%$ \\
\hline $41-50$ & 50 & $13.2 \%$ \\
\hline Above 50 & 19 & $5 \%$ \\
\hline
\end{tabular}

\begin{tabular}{|l|c|c|}
\hline Onset of the disease & Numbers & Parentage \\
\hline From childhood & 21 & $5.6 \%$ \\
\hline For months & 64 & $16.9 \%$ \\
\hline (2-3) years & 109 & $28.8 \%$ \\
\hline (5-10) years & 120 & $31.7 \%$ \\
\hline More than 10 years & 64 & $16.9 \%$ \\
\hline
\end{tabular}

\begin{tabular}{|l|c|c|}
\hline Regularity on medications & numbers & Percentage \\
\hline Yes & 283 & $74.3 \%$ \\
\hline No & 98 & $25.7 \%$ \\
\hline
\end{tabular}

\begin{tabular}{|l|c|c|}
\hline Taking other medications & Numbers & Percentage \\
\hline Yes & 274 & $64.5 \%$ \\
\hline No & 136 & $35.5 \%$ \\
\hline
\end{tabular}

\begin{tabular}{|l|c|c|}
\hline $\begin{array}{l}\text { The effect of these medication } \\
\text { on the hypothyroid treatment }\end{array}$ & Numbers & Percentage \\
\hline Yes & 120 & $32.3 \%$ \\
\hline No & 31 & $8.3 \%$ \\
\hline Don't know & 221 & $59.4 \%$ \\
\hline
\end{tabular}

\begin{tabular}{|l|c|c|}
\hline Stop the medication for a period & Numbers & Percentage \\
\hline Yes & 135 & $35.2 \%$ \\
\hline No & 248 & $64.8 \%$ \\
\hline
\end{tabular}

\begin{tabular}{|l|c|c|}
\hline $\begin{array}{l}\text { The reason for stopping the } \\
\text { medication }\end{array}$ & Numbers & Percentage \\
\hline feel better & 51 & $16.6 \%$ \\
\hline feeling of improvement & 24 & $7.8 \%$ \\
\hline Appears of side effect & 15 & $4.9 \%$ \\
\hline Availability of alternative & 11 & $3.6 \%$ \\
\hline probably does not benefit & 41 & $13.3 \%$ \\
\hline Other reasons & 151 & $49 \%$ \\
\hline Not stopped medication & 2 & $0.6 \%$ \\
\hline Lack of interest & 2 & $0.6 \%$ \\
\hline
\end{tabular}

\begin{tabular}{|l|c|c|}
\hline $\begin{array}{l}\text { Following the doctor's } \\
\text { instructions to take medicine }\end{array}$ & Numbers & Percentage \\
\hline Yes & 292 & $76.4 \%$ \\
\hline No & 90 & $23.6 \%$ \\
\hline
\end{tabular}

\begin{tabular}{|l|l|l|}
\hline $\begin{array}{l}\text { Following the same dose } \\
\text { recommended by the doctor }\end{array}$ & Numbers & Percentage \\
\hline Yes & 322 & $85 \%$ \\
\hline No & 57 & $15 \%$ \\
\hline
\end{tabular}

\begin{tabular}{|l|c|c|}
\hline Increased dose someday & Numbers & Percentage \\
\hline Yes & 102 & $27 \%$ \\
\hline No & 276 & $73 \%$ \\
\hline
\end{tabular}

\begin{tabular}{|l|c|c|}
\hline Reason of Increased dose & Numbers & Percentage \\
\hline $\begin{array}{l}\text { Feeling Non improvement } \\
\text { with the prescribed dosage }\end{array}$ & 84 & $27.3 \%$ \\
\hline Desire Quick improvement & 30 & $9.7 \%$ \\
\hline $\begin{array}{l}\text { Increase the desire of } \\
\text { improvement }\end{array}$ & 37 & $12 \%$ \\
\hline Others & 150 & $48.7 \%$ \\
\hline Not increase & 2 & $0.6 \%$ \\
\hline
\end{tabular}

\begin{tabular}{|l|c|c|}
\hline $\begin{array}{l}\text { numbers of times to doing the } \\
\text { thyroid functions test in a year }\end{array}$ & Numbers & Percentage \\
\hline $1-2$ & 197 & $53.1 \%$ \\
\hline $3-4$ & 104 & $28 \%$ \\
\hline $5-6$ & 44 & $11.9 \%$ \\
\hline 7 or More & 26 & $7 \%$ \\
\hline
\end{tabular}

\begin{tabular}{|l|c|c|}
\hline $\begin{array}{l}\text { Reason for doing more than 2 } \\
\text { test in ayear }\end{array}$ & Numbers & Percentage \\
\hline Changing dose & 143 & $39.4 \%$ \\
\hline Routine & 220 & $60.6 \%$ \\
\hline
\end{tabular}

\begin{tabular}{|l|c|c|}
\hline $\begin{array}{l}\text { Having sufficient knowledge } \\
\text { about the role of therapy in the } \\
\text { treatment of the disease }\end{array}$ & Numbers & Percentage \\
\hline Yes & 185 & $48.7 \%$ \\
\hline No & 195 & $51.3 \%$ \\
\hline
\end{tabular}

\begin{tabular}{|l|c|c|}
\hline Knowing when treatment stops & Numbers & Percentage \\
\hline Yes & 299 & $78.7 \%$ \\
\hline No & 81 & $21.3 \%$ \\
\hline
\end{tabular}

\begin{tabular}{|l|c|c|}
\hline $\begin{array}{l}\text { Knowledge about the extent of } \\
\text { continued treatment }\end{array}$ & Numbers & Percentage \\
\hline Yes & 60 & $31.6 \%$ \\
\hline No & 160 & $68.4 \%$ \\
\hline Hospital types & Numbers & Percentage \\
\hline Governmental & 217 & $58.2 \%$ \\
\hline Private & 91 & $24.4 \%$ \\
\hline Both & 64 & $17.4 \%$ \\
\hline
\end{tabular}

\begin{tabular}{|l|c|c|}
\hline $\begin{array}{l}\text { Regularity to visit a doctor } \\
\text { appointments and test }\end{array}$ & Numbers & Percentage \\
\hline Yes & 241 & $63.3 \%$ \\
\hline No & 140 & $63.7 \%$ \\
\hline
\end{tabular}

\begin{tabular}{|l|c|c|}
\hline $\begin{array}{l}\text { Using certain herbs or alternative } \\
\text { to the treatment of Thyroxin }\end{array}$ & Numbers & Percentage \\
\hline Yes & 53 & $14 \%$ \\
\hline No & 326 & $86 \%$ \\
\hline
\end{tabular}

\begin{tabular}{|l|c|c|}
\hline $\begin{array}{l}\text { Do you think that a hypothyroid- } \\
\text { dism completely treatable disease }\end{array}$ & Numbers & Percentage \\
\hline Yes & 182 & $47.9 \%$ \\
\hline No & 198 & $52.1 \%$ \\
\hline
\end{tabular}




\begin{tabular}{|l|c|c|}
\hline Cause of hypothyroidism & Numbers & Percentage \\
\hline Not known & 301 & $83.4 \%$ \\
\hline Surgical removal of gland & 18 & $5 \%$ \\
\hline Radiation & 10 & $2.8 \%$ \\
\hline Medication & 14 & $3.9 \%$ \\
\hline Others & 18 & $5 \%$ \\
\hline
\end{tabular}

\begin{tabular}{|l|c|c|}
\hline Traveling to found treatment & Numbers & Percentage \\
\hline Yes & 28 & $7.4 \%$ \\
\hline No & 349 & $92.6 \%$ \\
\hline
\end{tabular}

\begin{tabular}{|l|l|l|}
\hline $\begin{array}{l}\text { Receive help from the doctor to } \\
\text { follow medication }\end{array}$ & Numbers & Percentage \\
\hline Yes & 272 & $69.4 \%$ \\
\hline No & 120 & $30.6 \%$ \\
\hline
\end{tabular}

\begin{tabular}{|l|c|c|}
\hline Suffering from other diseases & Numbers & Percentage \\
\hline Yes & 126 & $33.2 \%$ \\
\hline No & 254 & $66.8 \%$ \\
\hline
\end{tabular}

\section{Data Analysis}

The Regularity on medicationis $74.3 \%$ among patients. Following The doctors Instructions to take medicine $76.4 \%$.Following the same dose recommended by the doctor $85 \%$. Doing thyroid functions test in ayear is $53.1 \%$ in $1-2$ years, $28 \%$ in $3-4$ years, $11.9 \%$ in 5-6years, $7 \%$ in 7 or more years.

The cause of hypothyroidism is unknown in $83.4 \%$

Regularity to visit appointments and test $63.3 \%$

Using certain herbs or alternative to the treatment of Thyroxin $14 \%$.

\section{Discussion}

Hypothyroidism, either primary or central, is gratifying to treat because of the ease and completeness with which it responds to thyroid hormone. 1,2

Treatment is nearly always with levothyroxine, and the proper use of this medication has been reviewed extensively. ${ }^{3}$

A primary advantage of levothyroxine therapy is that the peripheral deiodination mechanisms can continue to produce the amount of $\mathrm{T} 3$ required in tissues under the normal physiologic control. 4 There is, however, significant interest in combined T4 and T3 therapy. 5, 6
Levothyroxine has a 7-day half-life; about $80 \%$ of the hormone is absorbed relatively slowly (over hours) and it equilibrates rapidly in its extracellular distribution volume, therefore avoiding large post absorptive perturbations in fT4 levels. With its long half-life, omission of a single day's tablet has no significant effect and the patient may safely take an omitted tablet the following day. In fact, the levothyroxine dosage can be calculated almost as satisfactorily on a weekly, as on a daily, basis. Although T4 is well absorbed and does not require fasting, regular ingestion of levothyroxine on an empty stomach results in the least variation in serum TSH concentration. ${ }^{7}$

TSH level as an end point, has been suggested by many professional organizations. ${ }^{8}$ The availability in many countries of a multiplicity of tablet strengths with content ranging from 25 to $300 \mu \mathrm{g}$ allows precise titration of the daily levothyroxine dosage for most patients with a single daily tablet, improving compliance significantly.

The typical dose of levothyroxine, approximately 1.6 to $1.8 \mu \mathrm{g} / \mathrm{kg}$ ideal body weight per day, generally results in the prescription of between 75 and $125 \mu \mathrm{g}$ /day for women and 125 to $200 \mu \mathrm{g}$ /day for men. Replacement doses not need be adjusted upward in obese patients and should be based on lean body mass ${ }^{9}$. This dosage is about $20 \%$ greater than the T4 production rate owing to incomplete absorption of the levothyroxine. In patients with primary hypothyroidism, these amounts usually result in serum TSH concentrations that are within the normal range. Because of the 7-day half-life, approximately 6 weeks are required before there is complete equilibration of the fT4 and the biologic effects of levothyroxine. Accordingly, assessments of the adequacy of a given dose or the effects of a change in dosage, with rare exceptions such as pregnancy, should not be made until this interval has passed. This long half-life also means that it is safe for a patient to take any missed doses of T4 for up to a week after missing tablets.

Using levothyroxine from a single manufacturer reduces variability that may be relevant for patients, such as elderly, pregnant, and thyroid cancer patients, when close titration is required. 
Return of the serum TSH level to normal is therefore the goal of levothyroxine therapy in the patient with primary hypothyroidism. Some patients may require slightly higher or lower doses than generally used, owing to individual variations in absorption, and a number of conditions or associated medications may change levothyroxine requirements in patients with established hypothyroidism.

Although levothyroxine is absorbed in the stomach and small intestine, normal gastric acid secretion is required for complete absorption.10 Patients with impaired acid secretion on levothyroxine therapy require a $22 \%$ to $34 \%$ higher dose of levothyroxine to maintain the desired serum TSH. In those patients in whom acid secretion was normalized therapeutically, the levothyroxine dose returned to baseline. ${ }^{10}$

The use of levothyroxine as thyroid hormone replacement is a compromise with the normal pathway of $\mathrm{T} 3$ production, in which about $80 \%$ of $\mathrm{T} 3$ is derived from T4 5'-monodeiodination and approximately $20 \%(\sim 6 \mu \mathrm{g})$ is secreted directly from the thyroid gland.

The initial dose of levothyroxine prescribed depends on the degree of hypothyroidism and the age and general health of the patient. Patients who are young or middle-aged and otherwise healthy with no associated cardiovascular or other abnormalities and mild to moderate hypothyroidism (TSH concentrations of 5 to $50 \mathrm{mU} / \mathrm{L}$ ) can be given an initial complete replacement dose of about $1.7 \mu \mathrm{g} / \mathrm{kg}$ of ideal body weight. The resulting increase in serum $\mathrm{T} 4$ concentration to normal requires 5 to 6 weeks, and the biologic effects of T3 are sufficiently delayed that these patients do not experience adverse effects. At the other extreme, the elderly patient with heart disease, particularly angina pectoris, without reversible coronary lesions, should be given a small initial dose of levothyroxine $(25 \mu \mathrm{g} /$ day $)$, and the dosage should be increased in $12.5-\mu \mathrm{g}$ increments at 2- to 3-month intervals with careful clinical and laboratory evaluation.

The goal in the patient with primary hypothyroidism is to return serum TSH concentrations to normal, reflecting normalization of that patient's thyroid hormone supply. This usually results in a mid- to high-normal serum fT4. The serum TSH should be evaluated 6 weeks after a theoretically complete replacement dose has been instituted to allow minor adjustments to optimize the individual dose. ${ }^{11}$ In patients with central hypothyroidism, serum TSH is not a reliable index of adequate replacement, and the serum fT4 should be restored to a concentration in the upper half of the normal range. T4 dosing based on body weight and a serum fT4 in the upper reference range improved markers of thyroid hormone action and was superior to replacement with a combination of T4/T3. ${ }^{12}$

Although the adverse effects of the rapid institution of therapy are unusual, pseudotumorcerebri has been reported in profoundly hypothyroid juveniles between ages 8 and 12 years who were given even modest initial levothyroxine replacement. ${ }^{13}$ This complication appears 1 to 10 months after initiation of treatment and responds to acetazolamide and dexamethasone.

The interval between the initiation of treatment and the first evidence of improvement depends on the strength of dose given and the degree of the deficit. An early clinical response in moderate to severe hypothyroidism is a diuresis of 2 to $4 \mathrm{~kg}$. The serum sodium $(\mathrm{Na}+)$ level increases even sooner if hyponatremia was present initially. Thereafter, pulse rate and pulse pressure increase, appetite improves, and constipation may disappear. Later, psycho-motor activity increases and the delay in the deep tendon reflex disappear. Hoarseness abates slowly, and changes in skin and hair do not disappear for several months In individuals started on a complete replacement dose, the serum fT4 level should normalize after 6 weeks; a somewhat longer period may be necessary for serum TSH levels to return to normal, perhaps up to 3 months.

In some cases (e.g., myxedema coma, it is clinically appropriate to alleviate hypothyroidism rapidly. In such circumstances, liothyronine (25 
$\mu \mathrm{g}$ orally every 12 hours) can be administered if the patient can take medication by mouth.

When hypothyroidism results from administration of iodine-containing or antithyroid drugs, withdrawal of the offending agent usually relieves both the hypothyroidism and the accompanying goiter, although it is appropriate to provide interim replacement until the gland recovers its function. ${ }^{14,15}$ This is especially true for amiodarone, which may remain in tissues for up to a year.

After the first 6 months of therapy, the dose should be reassessed because restoration of euthyroidism increases the metabolic clearance of T4. A dose that was adequate during the early phases of therapy may not be so when the same patient is euthyroid owing to an acceleration in the clearance of thyroid hormone.

Under normal circumstances, the finding of a normal serum TSH level on an annual basis is adequate to ensure that the proper levothyroxine dose is being taken by the patient. If the serum TSH level is above the normal range and noncompliance is not the explanation, small adjustments, usually in $12-\mu \mathrm{g}$ increments, can be made with reassessment of TSH concentrations after the 6 weeks required for full equilibration have passed.

Thyroid hormone requirements may be altered in several situations. A reduction in replacement dosage may be required in women who are receiving androgen therapy for adjuvant treatment of breast carcinoma. ${ }^{16}$ Most other conditions or medications increase the levothyroxine requirement in patients receiving maintenance therapy. During pregnancy, the levothyroxine requirement is increased by $25 \%$ to $50 \%$ in most hypothyroid women, 17 and a prospective study demonstrated that the increased requirement occurs early in the first trimes $\neg$ ter. ${ }^{18,19,20}$ The required increment is higher in athyreotic patients compared to those with autoimmune hypothy-roidism. ${ }^{21}$ Athyreotic patients who are planning a pregnancy should be advised to increase the dose by around $30 \%$ as soon as the diagnosis is confirmed because the change in requirement appears soon after implantation.

Maternal T4 is critically important to the athyreotic fetus and in the normal fetus in the first trimester before fetal thyroid function and feedback regulation mature. ${ }^{20}$ Maternal hypothyroiddism has been associated with fetal loss, preterm delivery, and intellectual deficit in the offspring. ${ }^{18,19,22}$

A randomized prospective study in pregnant women with anti-TPO antibodies and normal range TSH demonstrated the benefit of levothyroxine treatment to prevent these complications. ${ }^{23}$

Other conditions in which levothyroxine requirements are increased ${ }^{2,24}$ include malabsorption due to bowel diseases, impaired gastric acid secretion, 10 and adsorption of levothyroxine to coadministered medications such as sucralfate, aluminum hydroxide, calcium carbonate, ferrous sulfate, lovastatin, or various resins. Certain medications, notably rifampin, carbamazepine, phenytoin, and sertraline, increase the clearance of levothyroxine by inducing CYP3A4 in the liver. Estrogen given to postmenopausal women may act in the same way, although the increases in D3 also play a role. ${ }^{16}$

Amiodarone increases levothyroxine requirements by blocking conversion of $\mathrm{T} 4$ to $\mathrm{T} 3$ and perhaps by interfering with T3-thyroid hormone receptor binding. ${ }^{23}$ Selenium deficiency is rare, but because it is rate limiting in the synthesis of D1, 4 any significant deficiency, such as may occur in patients receiving diets restricted in protein, may increase levothyroxine requirements.

Although the administration of excessive doses of levothyroxine causes accelerated bone loss in postmenopausal patients, most authorities believe that returning thyroid status to normal does not have adverse effects on bone density. 24,25 Administration of excessive doses also increases cardiac wall thickness and contractility and, in elderly patients, increases the risk of atrial fibrillation. $^{26,27}$

In some patients, TSH levels remain elevated despite the prescription of adequate replacement doses.28 This response is most often a 
consequence of poor adherence. The combination of normal or even elevated serum fT4 values and elevated TSH levels can occur if the patient does not take levothyroxine regularly but ingests several pills the day before testing. The integrated dose of levothyroxine over prior weeks is best reflected in the serum TSH level, and non adherent patients require careful education as to the rationale for treatment. Subtle changes in dietary habits, such as increasing the ingestion of bran-containing products, soy, or calcium or proton pump inhibitors, may decrease levothyroxine absorption, and their recognition requires a careful history. ${ }^{3,24,29}$

\section{Conclusion}

Hypothyroidism in Northern Borders region is health challenge. Patient awareness and compliance are non-satisfactory.

Many patients are unaware of dosage timing and food interaction with the drug

Many patients who concomitantly taking other medicines are unaware of these drug interaction with thyroxin and most of them have unstable dose replacement and test more frequently

Patient unawareness of the disease and replacement therapy resulted in patient shift to seek alternative therapy and many different health services.

\section{References}

1. Zulewski $H$, Muller $B$, Exer $P$, et al. Estimation of tissue hypothyroidism by a new clinical score: evaluation of patients with various grades of hypothyroidism and controls. J Clin Endocrinol Metab. 1997; 2:771- 776 .

2. Garber JR, Cobin RH, Gharib H, et al. American Association of Clinical Endocrinologists and American Thyroid Association Taskforce on Hypothyroidism. Clinical practice guidelines for hypothyroidism in adults: cosponsored by the American Association of Clinical Endocrinologists and the American Thyroid Association. Thyroid. 2012;22: 1200-1235.
3. Biondi B, Wartofsky L. Treatment with thyroid hormone. Endocr Rev. 2014;35:433-512.

4. Gereben B, Zavacki AM, Ribich S, et al. Cellular and molecular basis of deiodinase-regulated thyroid hormone signaling. Endocr Rev. 2008; 29:898-938.

5. Biondi B, Wartofsky L. Combination treatment with $\mathrm{T} 4$ and $\mathrm{T} 3$ : toward personalized replacement therapy in hypothyroidism? J ClinEndocrinolMetab. 2012;97:2256-2271.

6. Wiersinga WM, Duntas L, Fadeyev V, et al. 2012 ETA guidelines: the use of L-T4 + L-T3 in the treatment of hypothyroidism. Eur Thyroid J. 2012;1:55-71..

7. Bach-Huynh TG, Nayak B, Loh J, et al. Timing of levothyroxine administration affects serum thyrotropin concentration. $J$ Clin Endocrinol Metab. 2009;94:39053912.

8. Hennessey JV. Levothyroxine a new drug? Since when? How could that be? Thyroid. 2003;13:279-282

9. Santini F, Pinchera A, Marsili A, et al. Lean body mass is a major determinant of levothyroxine dosage in the treatment of thyroid diseases. J ClinEndocrinolMetab. 2005;90:124-127.

10. Centanni M, Gargano L, Canettieri G, et al. Thyroxine in goiter, Helicobacter pylori infection, and chronic gastritis. $N$ Engl J Med. 2006;354: 1787-1795.

11. Carr D, McLeod DT, Parry G, Thornes HM. Fine adjustment of thyroxine replacement dosage: comparison of the thyrotrophin releasing hormone test using a sensitive thyrotrophin assay with measurement of free thyroid hormones and clinical assessment. ClinEndocrinol (Oxf). 1988;28:325-333.

12. Slawik M, Klawitter B, Meiser E, et al. Thyroid hormone replacement for central hypothyroidism: a randomized controlled trial comparing two doses of thyroxine (T4) with a combination of T4 and 
triiodothyronine. J ClinEndocrinolMetab. 2007;92:4115-4122

13. Van Dop C, Conte FA, Koch TK, et al. Pseudotumorcerebri associated with initiation of levothyroxine therapy for juvenile hypothyroidism. $N$ Engl J Med. 1983;308:1076-1080.

14. Leung AM, Braverman LE. Iodineinduced thyroid dysfunction. Curr Opin Endocrinol Diabetes Obes. 2012;19:414419.

15. Bogazzi F, Tomisti L, Bartalena L, et al. Amiodarone and the thyroid: a 2012 update. J Endocrinol Invest. 2012;35:340348.

16. Arafah BM. Decreased levothyroxine requirement in women with hypothyroidism during androgen therapy for breast cancer. Ann Intern Med. 1994;121:247251.

17. Mandel SJ, Larsen PR, Seely EW, Brent GA. Increased need for thyroxine during pregnancy in women with primary hypothyroidism. $N$ Engl J Med. 1990;323:91-96.

18. Stagnaro-Green A, Abalovich M, Alexander E, et al. Guidelines of the American Thyroid Association for the diagnosis and management of thyroid disease during pregnancy and postpartum. Thyroid. 2011;21: 1081-1125.

19. De Groot L, Abalovich M, Alexander EK, et al. Management of thyroid dysfunction during pregnancy and postpartum: an Endocrine Society clinical practice guideline. $J$ Clin Endocrinol Metab. 2012;97:2543- 2565.

20. Alexander EK, Marqusee E, Lawrence J, et al. Timing and magnitude of increases in levothyroxine requirements during pregnancy in women with hypothyroidism. N Engl J Med. 2004;351:241-249.

21. Loh JA, Wartofsky L, Jonklaas J, Burman KD. The magnitude of increased levothyroxine requirements in hypothyroid pregnant women depends upon the etiology of the hypothyroidism. Thyroid. 2009;19:269-275.

22. Stagnaro-Green A, Pearce E. Thyroid disorders in pregnancy. Nat Rev Endocrinol. 2012;8:650-658.

23. Negro R, Mestman JH. Thyroid disease in pregnancy. Best Pract Res Clin Endocrinol Metab. 2011;25:927-943.

24. Barbesino G. Drugs affecting thyroid function. Thyroid. 2010;20: 763-770.

25. Marcocci C, Golia F, Bruno-Bossio G, et al. Carefully monitored levothyroxine suppressive therapy is not associated with bone loss in premenopausal women. $J$ ClinEndocrinolMetab. 1994;78:818-823.

26. Gogakos AI, Duncan Bassett JH, Williams GR. Thyroid and bone. Arch Biochem Biophys. 2010;503:129-136..

27. Franklyn JA. The thyroid - too much and too little across the ages. The consequences of subclinical thyroid dysfunction. ClinEndocrinol (Oxf). 2013;78:1-8.

28. Danzi S, Klein I. Thyroid hormone and the cardiovascular system. Med Clin North Am. 2012;96:257-268.

29. Benvenga S. When thyroid hormone replacement is ineffective? Curr Opin Endocrinol Diabetes Obes. 2013;20:467477

30. Benvenga S. When thyroid hormone replacement is ineffective? Curr Opin Endocrinol Diabetes Obes. 2013;20:467477. 